\title{
Effects of FDI on China Based on the Fuzzy Mathematics
}

\author{
Xiangyang Zhang \\ School of Graduate, Southwestern University of Finance and Economics, Chengdu 610074, China \\ E-mail: andy.letter@yahoo.com
}

Xin Li

College of International Business, Southwestern University of Finance and Economics

Chengdu 610074, China

E-mail: 1xin0111@gmail.com

\begin{abstract}
The international direct investment theory is one of domains which develop quickly in the international economics after the Second World War. Comparing with that obviously, the research of influencing factors about FDI (Foreign Direct Investment) develops very slowly. For a long time, FDI was thought to exert very important function to the economical increase of the host country, but in recent years, some negative influences occur. Base on some scholars' theoretical analysis, in this article, we utilize the method of fuzzy mathematics to comprehensively analyze the influencing factors of FDI on the host country, and translate the result into the data which can be directly compared to directly evaluate FDI.
\end{abstract}

Keywords: FDI, Fuzzy, Effect, Evaluation

\section{Theoretical summarization of the effect of FDI}

There is still no the last word about the influence of FDI to the economy of the host country. Though both the recent international trade theory and the economic growth theory lean to emphasize the positive influence of FDI to the host country, but there are not sufficient experimental researches can offer direct theoretical references for that sort of positive influence. After 1992, FDI begun to enter China cosmically, and the stage that China introduced foreign capital has turned into the deep development, and at the same time, some original contradictions and problems in the introduction of foreign investment have become more acute and complex.

Most scholars studied this problem from the technical view. The attraction to FBI is the effective method to promote the economic development of the host country, which can directly enhance the output of the host country, but can indirectly influence the output level of the host country through the technical spillage effect (Narula and Marin, 2003). But the technical transformation is decided by the absorption ability of domestic enterprises to large extents. The data of the English making industry showed that when domestic enterprises had similar production level with foreign companies, this sort of transformation was the most effective (Driffield and Taylor, 2002). Xutao (2003) supposed that FDI had different structure with domestic capital, and established an endogenesis growth model based on that, and also obtained that FDI had obvious promotion function for the technical advancement of China. Wang, Zhipeng and Li, Zinai (2004) established the quasi-endogenesis growth model considering the FDI spillover effect, and the result indicated that the long-term economic growth of the host country was decided by the ration of FDI and the domestic capital, and various regions must span certain human capital doorsill to obtain benefits from FDI. Many researches showed that the operators with deficient enough abilities were the important reason which induced the slow absorption of new technology (Lall, 2001). Furthermore, the technical spillage also occurred through the cooperation of transnational company with college or other research institutions (Santangelo, 2005).

However, other scholars deeply discussed the disadvantageous influences of FDI to the enterprise of the host country. Van Pottelsberghe and Lichtenberg (2001) indicated that FDI lacked the technical spillage effect. Baoqun and Lai, Mingyong (2002) studied the relation of FDI and China total factor productivity and capital output rate, and the result showed that the direct effect of FDI was obvious, but the technical spillage effect was little. Zhang, Jiangang (2006) thought that the requirement of technical monopolization and economy of the motivation of foreign traders' direct investment activity decided that foreign traders would not transfer technology to the enterprise of China. Many foreign traders set up various obstacles in the investment article, and achieved the long-term possession to the China market through the technical predominance. According to the "Solow residual", Hu, Lifa (2003) empirical analyzed the technical contribution of foreign capital in the economic growth of China, and thought that the technical contribution proportion of FDI to the economic growth of China was very limited.

Through the comparison to the recent researches about FDI, we can see that scholars generally studied the cause and 
effect relation of FDI and economic growth and discussed the influence of FDI to the regional economy of the host country. Starting from the view that the government introduces the foreign investment, this article mainly utilizes the method of fuzzy mathematics to discuss the effects of FDI to the host region.

\section{Empirical analysis of the effect of FDI to China}

\subsection{Active function of overseas direct investment to economic growth}

\subsubsection{Promoting the export growth and structure upgrade of China}

In 2006, the trade amount of foreign capital enterprise achieved 937.548 billion Yuan from January to November, with year on year increase of $25.49 \%$, and accounted for $58.24 \%$ of the national total trade amount, where, the export amount of foreign capital enterprise was 509.617 billion Yuan, with year on year increase of $27.90 \%$, and account for $58.24 \%$ of the national total export amount, and enhanced 0.3 percent compared to the same period of the last year. As viewed from the structure, the draught effect of the export of high-tech products of foreign capital enterprise to the national export growth continually ascended. The export amount of high-tech products was 223.378 billion Yuan with year on year increase of $30.53 \%$, and accounted for $87.99 \%$ of the national export amount of high-tech products (Document of the Ministry of Commerce of China, 2007, Issue No.25), which showed that the foreign capital enterprises drove the growth of China export and immitted energies for the optimization and update for the industrial structure. For example, the explanation of FDI by UN in "The Investment Report of 1992" was that the direct function of FDI to the technical advancement of the host country consisted in enhance the factor productivity through the technical spillover, changing the product structure, especial the structure of the export product, and forming a chain of "foreign capital- techinal spillover- industrial structure update".

\subsubsection{Increasing domestic employment opportunity of China}

The introduction of foreign capital can increase the demand of domestic labor force and extend the employment opportunities. Up to the late of 2006, the direct employment amount in foreign capital enterprises was about 28 millions, which accounted for above $10 \%$ of national urban non-agricultural labor population. Sha, Wenbing and Tao, Aiping (2007) applied the co-integration theory and relative theories and utilized the annual data from 1979 to 2005 to study the relation between FDI and employment growth of China, and the result indicated that the long-term balance relation existed between foreign traders' direct investment and employment amount of China. When the foreign traders' direct investment increased $1 \%$, it would bring the increase of $0.13 \%$ of employment amount of China for a long term (Sha, 2007, p.112-117). Furthermore, the employment opportunities created by the foreign direct investment enterprises exerted important function to release the social employment pressure of China.

\subsubsection{Participating in the formation of domestic capital and abating the deficiency of domestic construction capital}

China is a big developing country, and the deficiency of construction capital has very obvious restriction the economic development, and the foreign direct investment has been the important approach to finance for many regions. The FDI of 2004, 2005 and 2006 successively exceeded 60 billion dollars, and this amount achieved 63 billion dollars in 2006. From 2003 to 2006, the actual use sum of direct investment of foreign traders stably increased by the speed of annual $4.6 \%$. Through the combination of FDI with existing otiose production factors, new production ability would be formed, which can further promote the development of the economy of China.

\subsubsection{Introducing foreign advanced technology and management experiences}

The establishment of foreign capital enterprise can introduce foreign advanced technology for China, fill up some domestic technical blankness, and save precious time and large of scientific research charges, which can actively quicken the update step of China technical advancement and industry. For example, in the auto industry, the auto product technical level of China has entered the level of 1980s from 1950s in a few yeas. On the other hand, the foreign capital enterprises operate and manage according to the international traditions, which can bring a series of advanced management experience and train a passel of new management talents. The absorption and utilization of FDI have been the important and the most effective source that China obtains advanced technology and management experiences.

\subsection{Disadvantageous influences of FDI}

The rise and development of transnational companies are the most conspicuous change in international economic activities in recent fifty years. Proceeding from the motivation occupying the overseas market and obtaining profits, transnational companies invest abroad and establish subsidiary companies, implement activities of production change according to the principle of specialization division, and this type of international trade is controlled by the parent company which keeps the monopolized predominance of the capital, technical research and development, and sales, and transfers large of production stages which need using common labor force or heavy-laden pollution abatement to the developing country which has cheap labor costs and loose environment protection limitation. 
Therefore, the production and management of transnational company are not certainly propitious to the economic development of the host country.

2.2.1 The tendency of "exclusive foreign capital" and "large-scale" of foreign investment will increase the risk of industrial monopolization.

First, the opportunity that existing enterprises of China introduce new capital and technology through the mode of joint venture or cooperation obviously reduces. Second, the foreign capital enterprise is easier to be controlled or influenced by the transnational company outside China, and the difference between enterprises and the local social in the aspects of culture and value view may induce some social contradictions and conflicts and influence governmental policy direction and exertion effect. Third, the association of transnational company China economy is closer and closer, and the establishment and adjustment of production management decision also influence the economy of China and the industrial development with that, and accordingly the uncertainty of economic development and stability would increase. Fourth, because the transnational companies possess strong predominance of capital, technology and brand, they can easily form high industrial concentration in some important industrial domains, and accordingly the probability that few foreign capital enterprises develop industrial monopolization increases (Zhao, 2005, 2 December, 2005).

2.2.2 Weakening the technical research and development impetus of domestic enterprises

The foreign capital enterprises can reduce the developmental space of domestic enterprises. At present, the independent degree of local economy in many regions to the foreign capital continually increases, and by right of various predominance, foreign capital enterprises produce large "extrusion effect" to the same industrial domestic enterprises. And the domestic enterprises give up the market and brand, and gradually become one manufacturing factory in the global industrial chain of foreign capital enterprises, which self-innovation and self-development abilities are weakening. Furthermore, because domestic enterprises of China would face large risk in the process of enhancing their own technical abilities, they are always inclined to purchase existing technology and give up the investment to the research and investment, and accordingly restrict the development of their own technical abilities in the market competition.

\subsubsection{Bringing negative influences to the environment of China}

Many foreign companies established factory in China, because the environmental standard of China is very low and they can save much pollution abatement cost, which brings large hidden troubles for the depravation of China environment, and many pollution may exist ten years and even hundred years, at the same time, the pollution also turns into the living cost of China inhabitants, and many people even can not continual normal living, especial for those diseased crowds, the pollution pricks up the economic burden and may entail offspring.

\section{Establishing the fuzzy mathematical evaluation model}

\subsection{The fuzzy mathematical theory}

Supposed that there are two limited universe of discourse, $\mathrm{U}=\left\{u_{1}, u_{2}, \ldots \ldots u_{n}\right\}$ and $\mathrm{V}=\left\{v_{1}, v_{2}, \ldots \ldots v_{n}\right\}$, where, $\mathrm{U}$ and $\mathrm{V}$ represent two sets, and supposed that $\mathrm{U}$ represents the set composed by the evaluation factors and $\mathrm{V}$ represents the set composed by evaluation results. Through the fuzzy transformation,

$\mathrm{X}^{*} \mathrm{R}=\mathrm{Y}$

Where, $\mathrm{X}$ is the fuzzy subset in $\mathrm{U}$, which represents the evaluation factor and $\mathrm{Y}$ is the fuzzy subset in $\mathrm{V}$, which represents the evaluation result, and $\mathrm{R}$ is the matrix.

\subsection{The comprehensive evaluation to overseas funded enterprises}

The comprehensive evaluation to the foreign capital enterprises mainly considers the factors which are seen in Table 1.

The factors in Table 1 compose the universe of discourse, $\mathrm{U}=\left\{u_{1}, u_{2}, u_{3}, u_{4}, u_{5}, u_{6}, u_{7}\right\}$. To the evaluation result, we only consider excellent, good, common and bad degrees, which compose the evaluation result universe of discourse $\mathrm{V}=$ \{excellent, good, common, bad $\}$.

To the development of the industry of the enterprise, we can confirm it through experts' direct evaluation to the factor or the hypo-factor $\left(u_{1 i}\right)$. For example, to the evaluation to the development of the industry of the enterprise, the coefficient of "excellent" is $v_{11}$, the coefficient of "good" is $v_{12}$, the coefficient of "common" is $v_{13}$, and the coefficient of "bad" is $v_{14}$. In the same way, we can obtain the evaluation of other factors, 
$v_{i 1}, v_{i 2}, v_{i 3}, v_{i 4}\left(\mathrm{i}=2,3,4,5,6,7\right.$ respectively correspond with $\left.u_{2}, u_{3}, u_{4}, u_{5}, u_{6}, u_{7}\right)$, and the limitation condition is $v_{i 1}+v_{i 2}+v_{i 3}+v_{i 4}=1, \mathrm{i}=1,2,3,4,5,6,7$. According to above results, we can obtain the fuzzy transformation matrix.

$$
R=\left(\begin{array}{llll}
v_{11} & v_{12} & v_{13} & v_{14} \\
v_{21} & v_{22} & v_{23} & v_{24} \\
v_{31} & v_{32} & v_{33} & v_{34} \\
v_{41} & v_{42} & v_{43} & v_{44} \\
v_{51} & v_{52} & v_{53} & v_{54} \\
v_{61} & v_{62} & v_{63} & v_{64} \\
v_{71} & v_{72} & v_{73} & v_{74}
\end{array}\right)
$$

Under the condition without any weight,

$$
\mathrm{V}=\mathrm{U} * \mathrm{R} \text {. }
$$

When we evaluate the foreign capital enterprise, we mainly consider the development of the industry of the enterprise, the capital strength of the enterprise, and the technical innovation ability of the enterprise, in the next place, we consider other aspects, and then we distribute weights to these seven factors, i.e. $\mathrm{A}=\left(a_{1}, a_{2}, a_{3}, a_{4}, a_{5}, a_{6}, a_{7}\right)$. So the final evaluation result is

$$
\mathrm{V}=\mathrm{A} * \mathrm{R} \text {. }
$$

\subsection{The example}

Supposed that the evaluated objective is the transnational company of certain country this is just going to invest Chengdu, and the evaluation people who are selected from economic expert, environmental expert, human resource managers and common crowd, and the evaluation mode is to directly evaluate above seven evaluation factors according to four grades. The evaluation results are seen in Table 2.

According to the evaluation result, the matrix is

$$
R=\left(\begin{array}{llll}
0.6 & 0.3 & 0.2 & 0.2 \\
0.4 & 0.3 & 0.2 & 0.1 \\
0.5 & 0.2 & 0.1 & 0.2 \\
0.2 & 0.4 & 0.3 & 0.1 \\
0.1 & 0.2 & 0.3 & 0.1 \\
0.7 & 0.1 & 0.1 & 0.1 \\
0.5 & 0.3 & 0.1 & 0.1
\end{array}\right)
$$

Under the condition of weight distribution, suppose that $\mathrm{A}=(0.2,0.2,0.2,0.1,0.1,0.1,0.1)$, and finally we can obtain the comprehensive evaluation to the enterprise.

$$
\mathrm{V}=\mathrm{A}^{*} \mathrm{R}=(0.2,0.2,0.2,0.1,0.1,0.1,0.1)^{*}\left(\begin{array}{cccc}
0.6 & 0.3 & 0.2 & 0.2 \\
0.4 & 0.3 & 0.2 & 0.1 \\
0.5 & 0.2 & 0.1 & 0.2 \\
0.2 & 0.4 & 0.3 & 0.1 \\
0.1 & 0.2 & 0.3 & 0.1 \\
0.7 & 0.1 & 0.1 & 0.1 \\
0.5 & 0.3 & 0.1 & 0.1
\end{array}\right)
$$

According to the maximum and minimum algorithm, we can obtain

$\mathrm{V}=(0.2,0.2,0.2,0.2)$.

After normalization processing, we can obtain

$\mathrm{V}=(0.45,0.26,0.18,0.14)$.

The result of comprehensive evaluation shows that the degree of "excellent" is $45 \%$, the degree of "good" is $26 \%$, the degree of "common" is $18 \%$, and the degree of "bad" is $14 \%$. According to the decision principle of maximum 
subjection, this enterprise belongs to "excellent".

\section{Conclusions}

Through quantizing the uncertainty values by the fuzzy mathematics, in this article, we introduce different benefit groups to comprehensively evaluate FDI entering into the host country from different views, and this method breaks away from single past economic view, evaluate the real value of FDI objectively, and can help the policy decision maker to deeply judge and evaluate FDI.

\section{References}

Aswatch Damodaran. (2002). Investment Valuation. New York: John Wiley \& Sons, Inc.

Document of the Ministry of Commerce of China. (2007). Guiding Opinions of the General Office of the Ministry of Commerce of the People's Republic of China, on the Work of Absorbing Foreign Investment Nationwide in 2007. The Ministry of Commerce of China. Issue No.25.

Fan, Zhoutian. (2006). Fuzzy Matrix Theory and Application. Beijing: Science Press.

Sha, Wenbing \& Tao, Aiping. (2007). Effects of FDI on Employment. Finance \& Economics. No.4. p.112-117.

Solnik Bruno \& Mclenvey Dennis. (2004). International Investment. New Jersey: Parson Education, Inc.

Xie, kang. (2007). International Investment. Beijing: Publishing House of Electronics Industry. August, 2007.

Zhao, Jinping. (2005). Tendency Expectation of Foreign Capital Utilization in 2006. China Economic Times. 2 December, 2005.

Zvi Bodie, Alex Kane \& Alan J. Marcus. (2007). Essentials of Investments. The Mcgraw-Hill Company, Inc.

Table 1. Evaluation factors

\begin{tabular}{|l|l|c|}
\hline & \multicolumn{1}{|c|}{ Factor } & Element \\
\hline \multirow{4}{*}{ Enterprise } & Industrial situation & $u_{1}$ \\
\cline { 2 - 3 } & Capital strength & $u_{2}$ \\
\cline { 2 - 3 } & Technical innovation ability & $u_{3}$ \\
\cline { 2 - 3 } & Concern to the social welfare & $u_{4}$ \\
\cline { 2 - 3 } & Effects on the environment & $u_{5}$ \\
\hline \multirow{2}{*}{ Manager } & Management level & $u_{6}$ \\
\cline { 2 - 3 } & Manager's moral level & $u_{7}$ \\
\hline
\end{tabular}

Table 2. Experts' evaluation results

\begin{tabular}{|l|l|l|c|c|c|c|}
\hline \multirow{4}{*}{} & \multirow{2}{*}{ Factor } & \multirow{2}{*}{ Element } & \multicolumn{4}{|c|}{ Evaluation result } \\
\cline { 4 - 8 } & & & excellent & good & common & bad \\
\hline \multirow{5}{*}{ Enterprise } & Industrial situation & $u_{1}$ & 0.6 & 0.3 & 0.2 & 0.1 \\
\cline { 2 - 8 } & Capital strength & $u_{2}$ & 0.4 & 0.3 & 0.2 & 0.1 \\
\cline { 2 - 8 } & Technical innovation ability & $u_{3}$ & 0.5 & 0.2 & 0.1 & 0.2 \\
\cline { 2 - 8 } & Concern to the social welfare & $u_{4}$ & 0.2 & 0.4 & 0.3 & 0.1 \\
\cline { 2 - 8 } & Effects on the environment & $u_{5}$ & 0.1 & 0.2 & 0.3 & 0.4 \\
\hline \multirow{2}{*}{ Manager } & Management level & $u_{6}$ & 0.7 & 0.1 & 0.1 & 0.1 \\
\cline { 2 - 8 } & Manager's moral level & $u_{7}$ & 0.5 & 0.3 & 0.1 & 0.1 \\
\hline
\end{tabular}

